\title{
Combustion of Metals in Oxygen-Enriched Atmospheres
}

\author{
Lei Shao ${ }^{1}$, Guoliang Xie ${ }^{1}$, Cheng Zhang ${ }^{1}$, Xiao Liu ${ }^{1}$, Wanran Lu ${ }^{1}$, Guangyu He ${ }^{2}$ and \\ Jinfeng Huang 1 ,* \\ 1 State Key Laboratory for Advanced Metals and Materials, University of Science and Technology Beijing, \\ Beijing 100083, China; shaoleiustb@163.com (L.S.); leon_xq@126.com (G.X.); \\ zhangcheng1990zc@gmail.com (C.Z.); dxhzyq_fighting@163.com (X.L.); lwrygmljq@163.com (W.L.) \\ 2 Science and Technology on Plasma Dynamics Laboratory, Air Force Engineering University, Xian 710043, \\ China; hegy_22@126.com \\ * Correspondence: B0107355@ustb.edu.cn
}

Received: 11 November 2019; Accepted: 12 January 2020; Published: 15 January 2020

\begin{abstract}
Metal combustion is one of the main issues threatening service safety in oxygen-enriched atmospheres, leading to unexpected explosions in rocket engines. This paper reviews the recent development of metals combustion in oxygen-enriched atmospheres. Test methods under three typical conditions and combustion behaviors of three typical metals are mainly discussed. The microstructures of the combustion areas of tested samples in stainless steels, nickel superalloys, and titanium alloys are similar, containing an oxide zone, a melting zone, and a heat-affected zone. The development trend of metal combustion in oxygen-enriched atmospheres in the future is also forecasted.
\end{abstract}

Keywords: metals combustion; combustion behaviors; oxygen-enriched atmospheres

\section{Introduction}

With the development of technology, metals should meet the more and more strict requirements used in extreme environments. Most metals show a phenomenon that differs from oxidation or melting but is similar to the combustion of wood and nylon in oxygen-enriched atmospheres, called the combustion of metals [1]. Metals used in oxygen-enriched atmospheres therefore have a risk of combustion. Some metallic materials are difficult to be ignited in air but burn dramatically or even reach the explosive limit in oxygen-enriched atmospheres. When combustion does happen, it causes serious consequences. A series of catastrophic accidents have happened in liquid oxygen/kerosene engines. For example, an explosion occurred in the Johnson Space Center testing ground in 1980 caused by the combustion of a secondary aluminum valve when the oxygen pressure reached $6000 \mathrm{psi}$ (41.4 MPa). Another case happened in the Marshall Space Flight Center in 1992 when the shims and pistons made from 316 stainless steel combusted in a $35 \mathrm{MPa}$ oxygen pressure atmospheres, which led to the explosion of the testbed.

Because of the great hazard of metal combustion, researchers have extensively worked on controlling oxygen-fed fires in experimentation and production. The test methods for the combustion of metals can be traced back to 1921 when John. K. Mabbs tested several materials (hard rubbers, fibers, and metals) at a 13.8 MPa compression. With the utilization of liquid oxygen in rockets, the compatibility of materials with oxygen is a concern for the reliability and security of rocket engines. As a result, the American Society for Testing Material (ASTM) organized the Committee G-4 to write standards for the testing and selection of materials for oxygen service in 1975 [2]. The National Aeronautics and Space Administration (NASA) expanded great efforts in developing information on the compatibility of materials with oxygen. NASA instituted some tests to measure the compatibility, and the most common of those tests are ambient pressure liquid oxygen mechanical impact tests and high-pressure oxygen mechanical impact tests (introduced and detailed in the Test Methods section) [3]. Hust and Clark et al. 
reported the flammability of some pure metals [4], and the studies reported that copper showed an ignition temperature of about $1030^{\circ} \mathrm{C}$. This temperature is about $60^{\circ} \mathrm{C}$ below the melting point, and it does not ignite until the melting point when the oxygen pressure is below $34.5 \mathrm{MPa}$. Copper is therefore considered difficult to ignite. Iron was reported to ignite at $930^{\circ} \mathrm{C}$, which is $600{ }^{\circ} \mathrm{C}$ lower than its melting point. Others reported that the ignition temperature of iron was $1315^{\circ} \mathrm{C}$, which was also obviously below the melting point [5]. As a result, even in ambient pressure, the resistance to the combustion of iron is poor. Junichi Sato, a Japanese researcher, studied the flammability of iron in high-pressure, oxygen-enriched atmospheres [6]. He found that when the hot iron burned in oxygen, the oxide and natural convection influenced the combustion property. The chemical characters of magnesium were very active, and $\mathrm{Mg}$ alloys were prone to oxidation and burning. The ignition temperature of pure magnesium was about $630-640^{\circ} \mathrm{C}$ in the air [7-10]. Some elements can improve its ignition temperature directly, like $\operatorname{Er}[11,12], \mathrm{Gd}[13], \mathrm{Y}$ [14-16], and other rare earth elements [17,18], but the major alloying elements of $\mathrm{Mg}$, such as $\mathrm{Al}$ [16,19], $\mathrm{Zn} \mathrm{[20],} \mathrm{Mn}$ [21], and $\mathrm{Cd}$ [22,23], reduce the ignition temperature. For example, the ignition temperature reached $500{ }^{\circ} \mathrm{C}$ when $20 \mathrm{wt} \% \mathrm{Al}$ was added to $\mathrm{Mg}$ alloys [19], and $\mathrm{Zn}$ also reduced the $\mathrm{Mg}$ alloys' ignition temperature; its effect was smaller to that of $\mathrm{Al}$ [20]. Aluminum showed an ignition temperature higher than its melting point, which was described as the melting point of alumina $\left(2050^{\circ} \mathrm{C}\right)[4,5]$. Nickel was observed to ignite at its melting temperature $[4,5]$. Silver cannot be ignited at any oxygen pressure $[4,5]$. The more thorough works in this field have been studied. The composition of metallic materials, the structure of oxide, and the phase transformation were important parts of flammability. Dreizin reported the phase transformation in the combustion process [24]. The experimental results showed that the reaction and the oxygen in solid solution induced the phase transformation. Tayal and Wilson studied the relationship between the composition and flammability of a nickel-based binary alloy [25]. They found that the threshold of pressure changed greatly after the addition of different contents of alloy elements. Nihart and Smith found that the nickel, brass, and Inconel $600(76 \mathrm{Ni15Cr} 8 \mathrm{Fe})$ showed excellent properties of resistance to combustion, but those of austenitic stainless steel and aluminum were relatively poor [26]. Kirschfeld and Miller compared the combustion resistance of several common alloys. They found that Monel $400(66.5 \mathrm{Ni} 31.5 \mathrm{Cu})$ had the best combustion resistance, followed by 304 stainless steels, and the combustion resistance of gray cast irons was better than carbon steels $[27,28]$. Titanium can be ignited in air at about $1600{ }^{\circ} \mathrm{C}$ because of its low thermal conductivity, high oxygen affinity, and high combustion heat [29-32]. The combustion characteristics of different titanium alloys such as TC4 [33-35], TC11 [36,37], and Ti40 [38,39] were studied by the friction method. The result showed that the contact force and oxygen concentration corresponding to ignition were found to obey a parabolic relationship [36-38]. All the combustion behaviors can be summarized as three burning models, called liquid phase burning model, vapor phase burning model, and mixed-phase burning model [40]. In the liquid phase burning model, the energy provided by the promoter melted the sample end and the oxidation reaction between the liquid sample and oxygen occurred in the melting oxide mass. For the case of the vapor phase burning model, the oxidation reaction between metallic vapor and oxygen occurred in the gas phase around the molten mass. The mixed-phased burning model was a mixture of the two models.

Accidents indicate that the combustion of metals in oxygen-enriched atmospheres is a novel failure mode without any preliminaries at all, which causes severe limitations on their applications. In order to understand the theoretical basis and to evaluate service safety, a brief review of the combustion behavior of metals is discussed in this paper. 


\section{Test Methods}

Liquid and gaseous oxygen are widely used in industry and spaceflight. In oxygen-enriched atmospheres, if the heat from the outside and oxidization is greater than that being consumed, the temperature of metal increases, followed by ignition. As a result, the combustion of metals is a pretty realistic problem. In order to reduce the probability of the fire, the metallic materials should be tested in oxygen-enriched atmospheres to ensure their security. The US carried out systematic studies the on combustion of metallic materials and outlined the relevant standards in the ASTM. Some widely used methods are introduced in this paper.

\subsection{NASA Mechanical Impact Tests}

Out of all the tests on combustion of metal, the most widely used method is the NASA mechanical impact test. Almost all of aerospace materials should be tested before used. The principle and the process are detailed in this paper.

\subsubsection{Ambient Pressure Liquid Oxygen Mechanical Impact Tests [41-44]}

In this test, a plummet free falls from the preset height to a striker pin resting directly on the test specimen immersed in liquid oxygen. In order to test the combustion resistance, the maximum impact energy, $98 \mathrm{~N} \cdot \mathrm{M}$, is provided by dropping a $9.09 \mathrm{~kg}$ plummet from a $1.1 \mathrm{~m}$ high shelf to a striker pin with a diameter of $12.7 \mathrm{~mm}$ in contact with the specimen with a $17.5 \mathrm{~mm}$ diameter. The schematic diagram is shown in Figure 1. Reactions are generally indicated by an audible explosion, light emission, or material charring in elevated pressure tests. Lower impact energies are selected by changing the drop height of the plummet. Twenty test drops are normally performed in each test. This test method evaluates the compatibility of materials for use in oxygen and oxygen-enriched atmospheres.
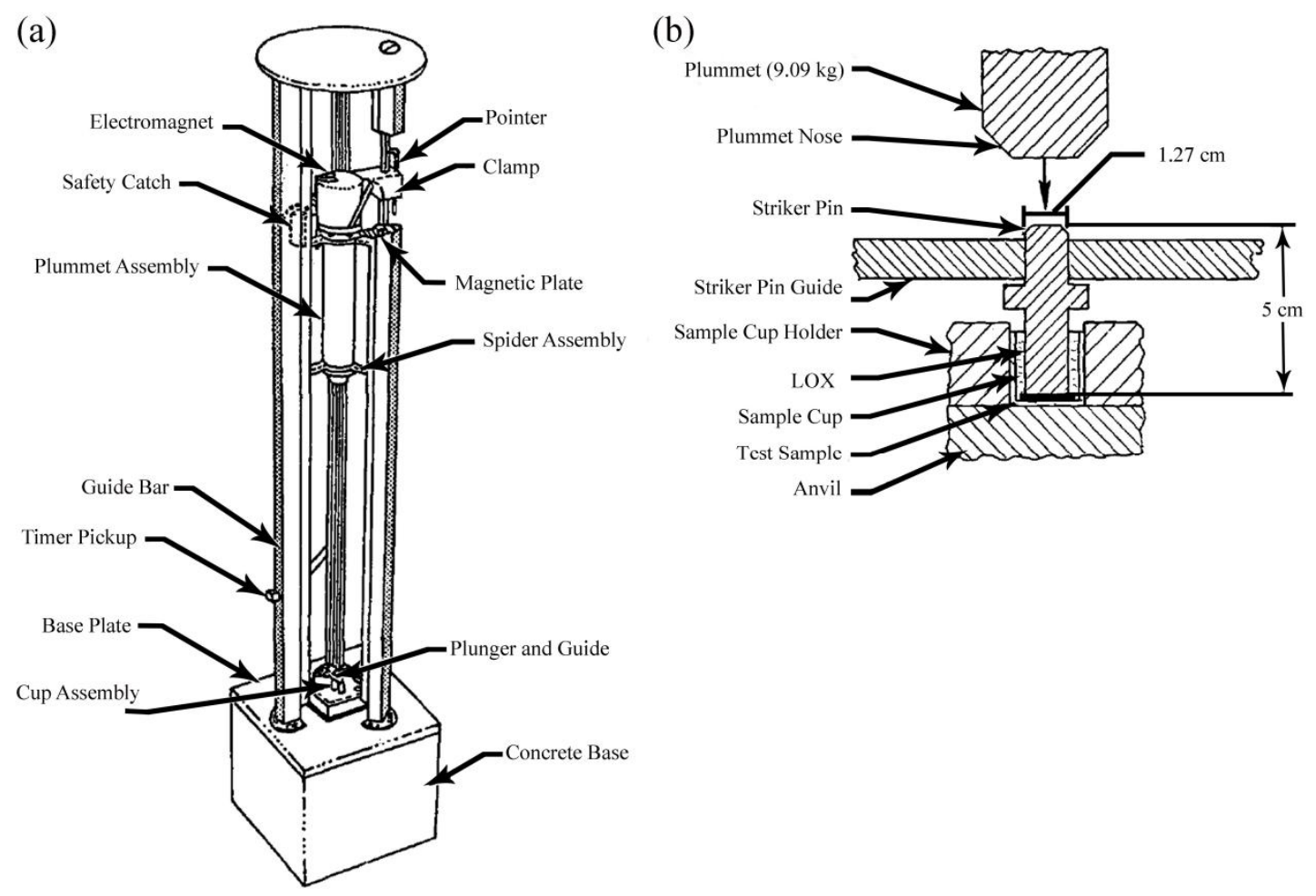

Figure 1. (a) Diagram of the ambient pressure liquid oxygen mechanical impact test facility. (b) The striker pin assembly detail, reproduced from [41] with permission from ASTM, 2019. 


\subsubsection{High-Pressure Oxygen Mechanical Impact Tests $[41,43,45]$}

This test method is similar to the previous method, as both of them are designed to expose material samples to mechanical impacts, as shown in Figure 2. The facility consists of a test chamber that can bear the $34 \mathrm{MPa}$ pressure, a plummet dropping from the preset height, and a striker pin that transmits the energy to the test sample. The higher the energy threshold, the better the combustion resistance. As a method to evaluate the combustion resistance to mechanical impact, the NASA mechanical impact test has the widest use.
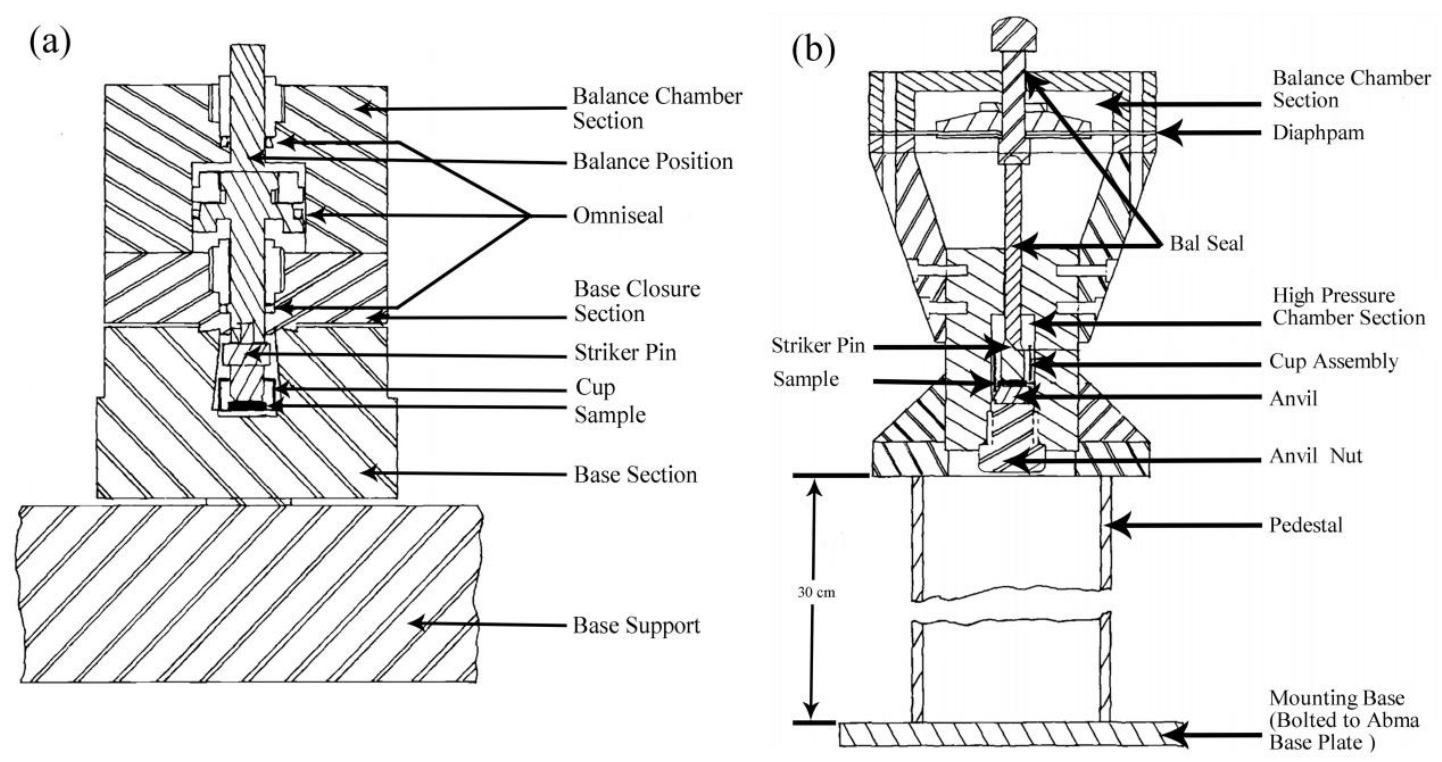

Figure 2. (a) High-pressure oxygen mechanical impact test chamber in the Marshall Space Flight Center. (b) Mechanical impact test chamber in the White Sands Test Facility, reproduced from [41] with permission from ASTM, 2019.

\subsection{Promoted Combustion Tests $[46,47]$}

When polymers are present in aero engines, they can be easily ignited in high-temperature oxygen-enriched atmospheres. They can then possibly ignite tiny metallic materials, and through this process, the chain reaction can be created and ultimately lead to explosions.

This test method confirms the pressure threshold and oxygen index that sustain candle-like burning of a standardized sample of metallic materials, as shown in Figure 3. The apparatus comprises a chamber, which is sufficiently large to ensure the variation of gas pressure and purity is lower than $10 \%$ during burning. Samples are usually configured as rods with the size of $\Phi 3.175 \times 101 \mathrm{~mm}$. In order to provide sufficient energy to ignite, the promoter is attached to the end of the samples. Aluminum $(0.2 \mathrm{~g})$ is considered as the promoter to provide about $7 \mathrm{~kJ}$ of energy, and in the other case, $0.15 \mathrm{~g}$ of magnesium can produce the same energy as aluminum when combusted. During the combustion, the temperature of the sample can be recorded by a temperature sensor and the entire combustion process is recorded by a video camera. The samples are installed vertically in specimen clamps, and the promoter is fitted onto the end of the specimen. The chamber is pumped to vacuum then filled with gaseous oxygen. If the sample is not ignited, five additional tests are performed using one set of conditions. Tests are repeated at various oxygen pressures until the threshold pressure is established. This test apparatus can also measure the relationship between the sample size and configuration with the threshold at one pressure. 


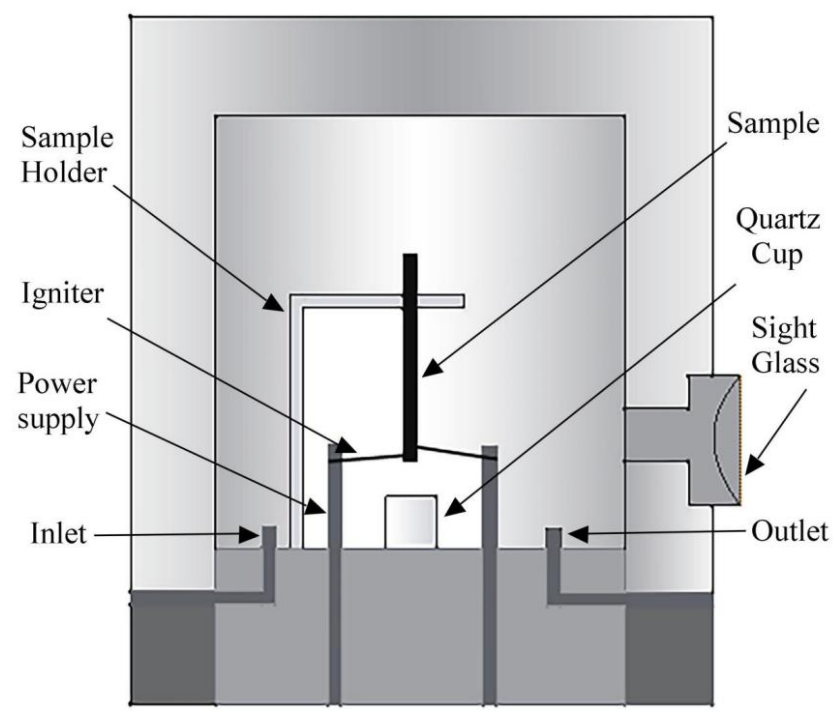

Figure 3. Diagram of promoted combustion test facility, reproduced from [46] with permission from ASTM, 2020.

\subsection{Friction-Induced Ignition Tests [48,49]}

The friction-induced ignition of metals confused the designers and users of pumps, compressors, and oxygen components. The ignition of metallic materials in oxygen-enriched atmospheres by friction heating is the dominant ignition source in many cases of combustion, and this test shows the friction heating sensitivity of metals and alloys. The apparatus comprises a cylindrical chamber that can bear $65 \mathrm{MPa}$ of pressure, and the schematic diagram is shown in Figure 4. There are two test samples, which consist of two identical hollow cylinders. One sample is fixed on the chamber wall, and the other is fixed on a shaft, which is connected to a drive motor. The drive motor can provide the maximum rotating speed of 20,000 rpm; meanwhile, it can also provide the capability of applying up to $4450 \mathrm{~N}$ of load on the test samples. The product of the contact pressure $P$ and the average liner surface velocity $\mathrm{v}$ can represent the capability of combustion resistance. The higher the product of Pv, the better the combustion resistance capability.

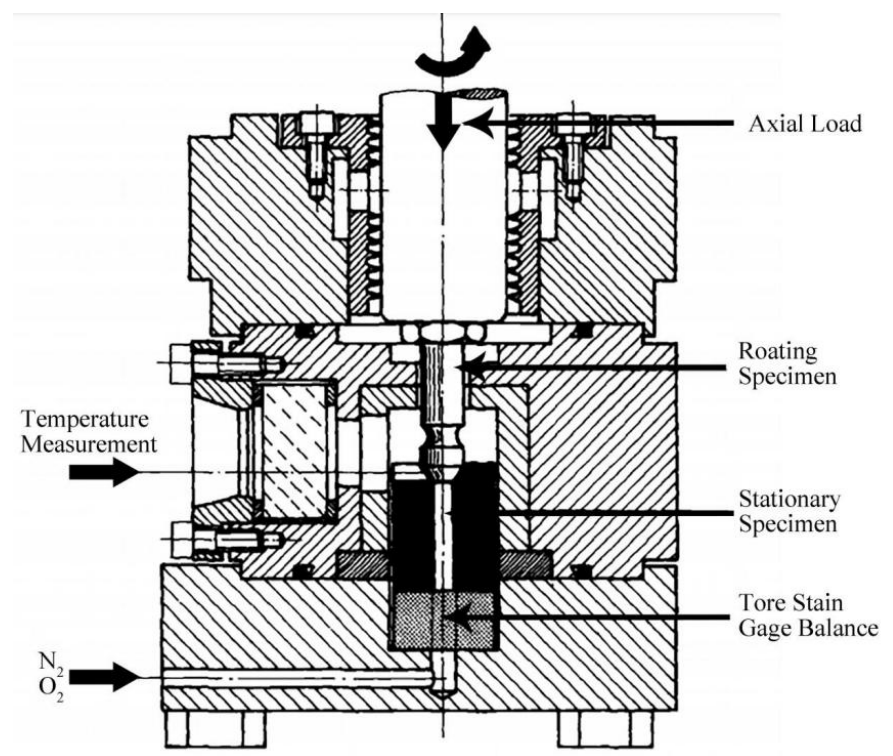

Figure 4. Diagram of friction-induced ignition facility, reproduced from [49] with permission from ASTM, 2020. 


\subsection{High-Velocity Particles Impact Tests [50,51]}

In order to increase the thrust of liquid oxygen/kerosene rocket engines, some metallic particles are mixed up with fuel. Using the burning of particles to create higher temperatures thus provides a higher thrust. For a long time, high-velocity particles impacting the surface of alloys had been suspected to be one reason for combustion in oxygen-enriched atmospheres. Further research has not been conducted because of a lack of instruments that can make an effective assessment. The NASA White Sands Test Facility (WSTF) used some test methods to evaluate the oxygen capability of metals and alloys. One of those methods is a high-velocity particle impact test.

The apparatus at WSTF consists of three major sections: the gas inlet and flow straightener, the particle injector and converging nozzle, and the diverging nozzle and test sample mounting fixture, as shown in Figure 5. The gaseous oxygen with subsonic velocity enters the chamber then flows through the flow straightener section. The velocity of the gas is accelerated to Mach 1 when the gas enters the converging nozzle. Then the velocity is continuously accelerated and reaches to about Mach 3.5 when the gas flows through the diverging nozzle. The gas then enters a short section with a constant cross-sectional area used to establish a constant gas velocity. Meanwhile, particles are injected, mixed with the gas and impact on the samples.

(a)

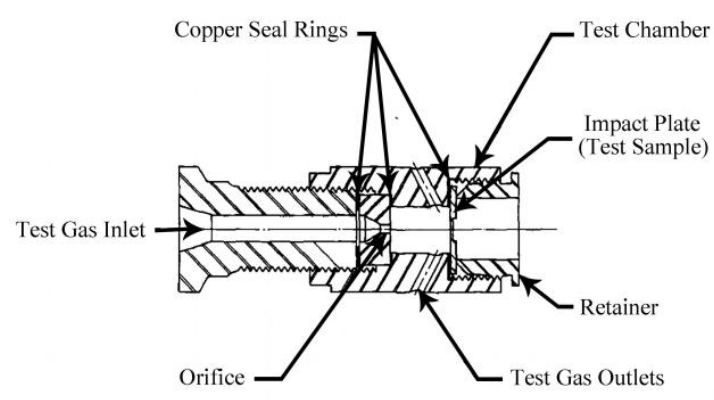

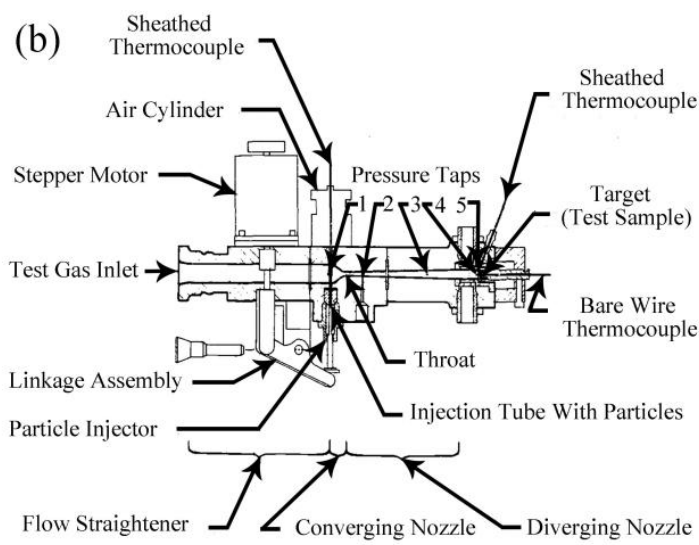

Figure 5. (a) First generation sonic velocity impact chamber; (b) ameliorated sonic velocity impact facility, reproduced from [50] with permission from ASTM, 2019.

\section{Combustion Behaviors of Stainless Steels}

Stainless steels are import alloys in oxygen systems, which are widely used in valves and vessels. However, several decades ago, some researchers suggested that stainless steels were easily ignited in oxygen-enriched atmospheres. As a result of these data, critical components made from stainless steels and used in oxygen-enriched atmospheres were used less frequently. In the 1980s, more realistic data on metallic material flammability were obtained, which indicated that stainless steels are significantly more combustion-resistant than carbon steels. Despite this, the combustion resistance of stainless steels is not as good as nickel-based superalloys, but the cost of stainless steels is much cheaper than superalloys. The stainless steel ignition below the threshold pressure might yield more damage than would occur to the nickel-based alloys. Some combustion behaviors of commonly used stainless steels are discussed below.

The microstructures of stainless steels after combustion are shown in Figure 6, consisting of heat-affected zone (influenced by the combustion heat but no melting), melting zone (melting but no oxide), and oxide zone (the product of burning). The results of scanning electron microscopy (SEM) proved the crystal structures in alloy base present no obvious deformation, and there are no internal oxidation partials. The melting zone was influenced by the combustion heat, and the internal oxidation phenomenon could be found. The part close to the combustion front showed serious internal oxidation, and the many holes may exist because of the shrinkage during the solidification. The oxide zone is 
located in the outermost area of the sample with a porous structure, and this zone consisted of mixed oxide, which burned several elements in the alloy.

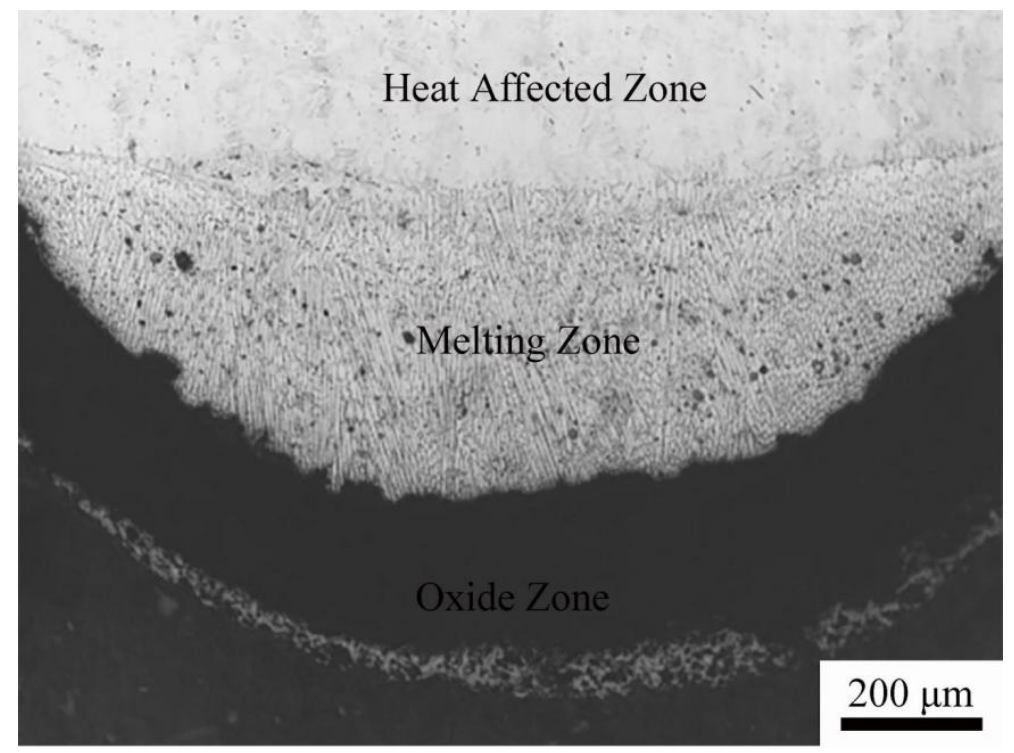

Figure 6. SEM photographs of combustion area of a stainless steels, reproduced from [52] with permission from ASTM, 2020.

The 316 type of stainless steel is a workhouse in the chemical industry and used in pressure vessels and piping up to $816^{\circ} \mathrm{C}$. This type of stainless steel has the nominal composition of $6 \mathrm{Cr} 17 \mathrm{Ni} 12 \mathrm{Mo} 2$. It is an austenitic alloy that has remarkable corrosion resistance in harsh conditions. It is a potential candidate for oxygen-enriched atmospheres. The threshold pressure of 316 stainless steel is about 3.45 $\mathrm{MPa}$ with a $3.2 \mathrm{~mm}$ diameter at ambient temperature [52,53]. The entire specimen is consumed when the oxygen pressure is above the threshold pressure, and the specimen will self-extinguish when the pressure is below the threshold pressure. With increasing pressure, the burning velocity of 316 stainless steel raises. The specimen sustains candle-like, gentle burning at $3.45 \mathrm{MPa}$, and the burning velocity reaches $15.8 \mathrm{~mm} / \mathrm{s}$ at $69 \mathrm{MPa}$ [54]. Some researchers indicated that increasing the temperature of metallic materials often leads to lower burning pressure. As for 316 stainless steel, it has been shown to combust at a pressure of $3.45 \mathrm{MPa}$ in $100 \%$ oxygen at ambient temperature. However, when the temperature of the specimen rod is increased to $875^{\circ} \mathrm{C}$, the rod combusts at a pressure of $0.2 \mathrm{MPa}$ [55].

Austenitic alloys such as 304 type stainless steel are commonly used and have a wide temperature range of $-196^{\circ} \mathrm{C}-800^{\circ} \mathrm{C}$. The major application of 304 stainless steel includes use in the foodservice and medical industries. The nominal composition of 304 stainless steel is $6 \mathrm{Cr} 19 \mathrm{Ni10}$. The threshold pressure of 304 stainless steel with a $6.4 \mathrm{~mm}$ diameter rod is $10.34 \mathrm{MPa}$, lower than the same size specimen made by 316 stainless steel, which is $17.23 \mathrm{MPa}$ [52]. When the environmental temperature is raised to $538{ }^{\circ} \mathrm{C}$, the burn length of 304 stainless steel specimen is $6.3 \mathrm{~mm}$ at $0.7 \mathrm{MPa}$ pressure, however the burn length of 316 stainless steel specimen is only $3.7 \mathrm{~mm}$ at the same condition [55]. From these data, we can see that the combustion resistance of 316 stainless steel is better than 304 . The reason may be explained by the nickel content of 316 stainless steel being higher than that of 304, as the heat of combustion of nickel is pretty low, and the nickel element shows the perfect combustion resistance. The higher the content of nickel, the better the combustion resistance.

The 347 stainless steel is a chromium-nickel austenitic stainless steel, which is stabilized by columbium plus tantalum addition. The addition of columbium and tantalum can minimize the potential for sensitization and intergranular corrosion, which may be troublesome for 304 stainless steel in certain environments. The threshold pressure of 347 stainless steel is $2.07 \mathrm{MPa}$ in pure oxygen at ambient temperature, much less than that of 316 and 304 stainless steel [52,56]. The 321 type of 
stainless steel is chromium-nickel-titanium austenitic stainless steel. Its properties are similar to 304 stainless steel and it benefits from the addition of titanium. The 321 stainless steel shows ideal intergranular corrosion resistance and high-temperature strength. The extinguishing pressure of 321 stainless steel is lower than $3.45 \mathrm{MPa}$. The burn length for the rod configuration of 321 stainless steel is $41.3 \mathrm{~mm}$ at $0.32 \mathrm{MPa}$ of oxygen pressure, longer than 316 stainless steel [53], because 321 stainless steel contains titanium element, and the combustion heat of titanium is 19,716.1 J/g, much higher than any other elements in stainless steel.

In view of the above-mentioned facts, the stainless steels combust at relatively low pressure, so some critical components in rocket engines may be made by superalloys to ensure the components will not burn at higher pressure.

\section{Combustion Behaviors of Nickel Superalloys}

The nickel alloys show the perfect properties of hard facing, high strength, corrosion resistance, and high-temperature service, so they are frequently used in the aerospace industry. They also have excellent combustion resistance in oxygen-enriched atmospheres. The microstructures of nickel superalloys after combustion are shown in Figure 7, and the microstructures are similar to those of stainless steels.

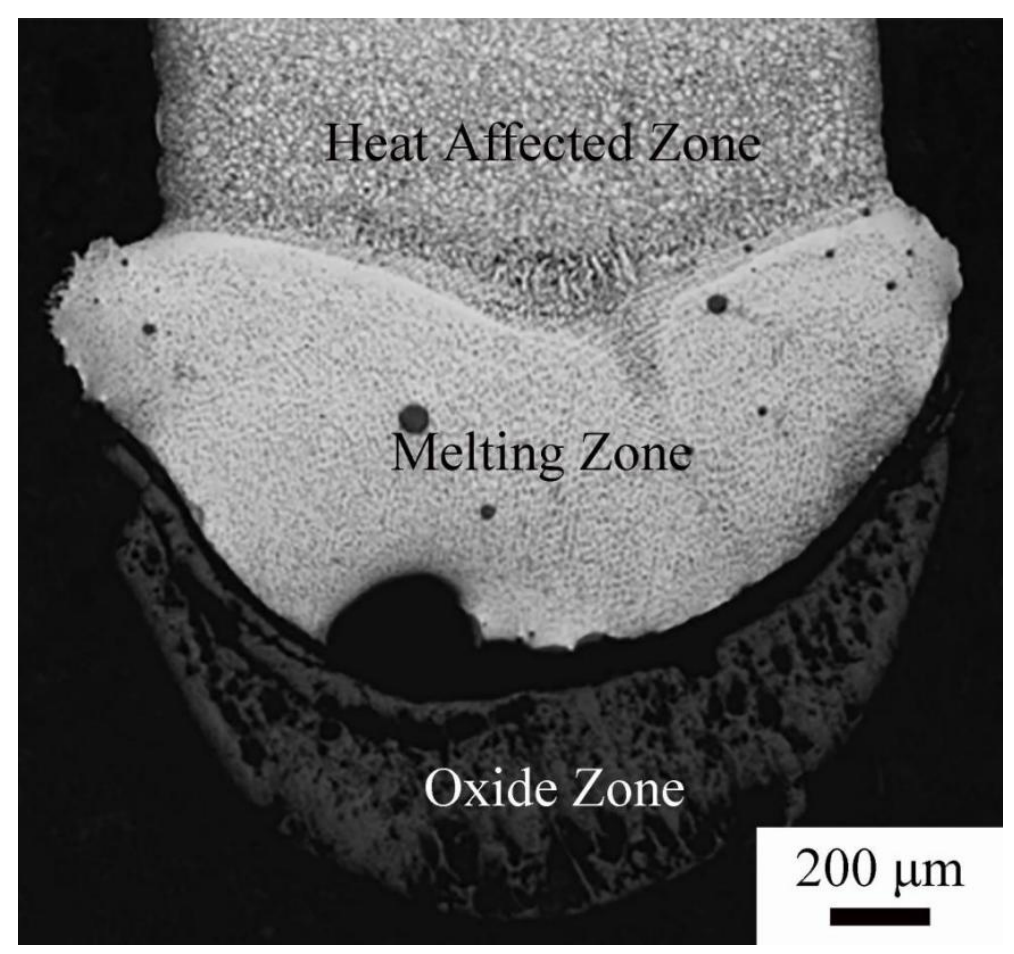

Figure 7. SEM photographs of combustion area of a nickel alloy, reproduced from [57] with permission from ASTM, 2020.

Nickel is one of the most combustion-resistant elements, as its threshold pressure is greater than $69 \mathrm{MPa}$. The flammability of nickel-based binary alloys is strongly influenced by the alloying additions. For example, the nickel-chromium alloys containing up to $30 \mathrm{wt} \%$ chromium have a threshold pressure similar to nickel. When the chromium content increases to $37.1 \mathrm{wt} \%$, the threshold pressure plummets down to $2.1 \mathrm{MPa}$ [58]. An explanation for this phenomenon is that if the quantities of alloying elements are to nickel, which form the majority of nickel primary solid solution, the binary alloys show a threshold pressure corresponding to nickel, but if they form a critical number of intermetallic compounds, the threshold pressure of the binary alloys is significantly lower than that of nickel. The flammability of industry nickel alloys is different from the binary alloys. 
Inconel 718 is a nickel-chromium-iron alloy with the nominal composition of 55Ni15.5Cr17.5Fe. It is a precipitation-hardenable alloy. Its threshold pressure is $6.89 \mathrm{MPa}$, higher than that of 316 stainless steel $[53,58]$. The burning velocity of Inconel 718 for a $3.2 \mathrm{~mm}$ diameter rod configuration is $10.9 \mathrm{~mm} / \mathrm{s}$ at threshold pressure. When the pressure is increased to $69 \mathrm{MPa}$, the burning velocity reaches $13.7 \mathrm{~mm} / \mathrm{s}$ [52]. Inconel 600 is a high-nickel alloy that might be considered as a standard for the comparison of high-temperature alloy. It has the nominal composition of $76 \mathrm{Ni} 15 \mathrm{Cr} 8 \mathrm{Fe}$. The threshold pressure of Inconel 600 is $17.2 \mathrm{MPa}$, much higher than Inconel 718. This may be because the nickel content of Inconel 718 is lower than that of Inconel 600 but the iron content is higher than Inconel 600. The combustion heat of iron is $7388.3 \mathrm{~J} / \mathrm{g}$, almost twice that of nickel, and the combustion product of iron is $\mathrm{Fe}_{2} \mathrm{O}_{3}$, which has a polyporous texture. This texture is beneficial to oxygen transmission and accelerates the progress of combustion. Inconel 625 has a threshold pressure of 17.24 MPa, a little more than Inconel $600[55,58]$. One possible reason is that the chromium content in Inconel 625 is higher than Inconel 600, and a compact, high-melting-point oxidation film, $\mathrm{Cr}_{2} \mathrm{O}_{3}$, on the surface of the combustion product can be formed during the combustion, and this oxidation film can restrain the combustion. Another reason is that there is $9 \mathrm{wt} \%$ molybdenum in Inconel 625. The combustion heat of molybdenum is not as high as chromium and iron, but the combustion product of molybdenum is a volatile oxide, which influences the flammability. Monel $\mathrm{Ni}-\mathrm{Cu}$ alloys are industrial gas industry workhouses where combustion resistance in high-purity oxygen at high pressure is required. Monel 400 has a nominal composition of $66.5 \mathrm{Ni} 31.5 \mathrm{Cu}$, which shows the highest threshold pressure of $69 \mathrm{MPa}[52,54,58]$, and at any pressure below $69 \mathrm{MPa}$, no burning velocity is calculated. Overall, the combustion resistance of superalloys is much better than stainless steels because of the high quantities of nickel [57,59].

\section{Combustion Behaviors of Titanium Alloys}

Titanium and its alloys have a broad application in the aircraft industry owing to their high strength, low density, and excellent corrosion resistance [60,61]. However, titanium alloys can be ignited easily by the high-speed friction and severe impact under high pressure, which is called "titanium fire" [62]. Titanium fire spreads quickly, and it is hard to control because of the low thermal conductivity and high combustion heat [63], so the titanium fire accidents have led to some catastrophic accidents.

Compared to titanium, copper and aluminum show little risk of combustion [64]. The reason for this is that the oxidation process of copper and aluminum is self-suppressive in the full temperature range whether before melting or after melting. In this case, the oxygen transport to the fresh metal is hindered by the oxide layer $[65,66]$. Generally, the thickness of the oxide layer and time exhibit a logarithmic or exponent relation, which could restrain the combustion process. As a result, the oxidation proceeds in an isothermal way, and only removes the oxide layer when the temperature rises. Titanium has a combustion risk due to its own characteristics. There is a series of oxides of titanium, including $\mathrm{Ti}_{3} \mathrm{O}_{5}, \mathrm{TiO}, \mathrm{Ti}_{2} \mathrm{O}_{3}$, and $\mathrm{TiO}_{2}$, and the density of these oxides reduces gradually $[33,34]$. In the service temperature, $\mathrm{TiO}_{2}$ is generated firstly, and the titanium dissolves more oxygen with a rise in temperature. Then, the exchange reaction happens, forming the low-value oxides, which show high density, leading to the broken oxygen layer. Once the oxygen layer is broken, a lot of oxygen reacts with fresh metal and gives off plenty of heat. The metal is ignited when the temperature reaches the ignition point.

To solve this problem, numerous works have been conducted on titanium combustion behavior and have tried to develop new burn-resistant titanium alloys. Currently, two typical burn-resistant titanium alloys have been designed, one type is $\mathrm{Ti}-\mathrm{Cr}-\mathrm{V}$ system alloys, and the other type is $\mathrm{Ti}-\mathrm{Cu}$ system alloys [38]. The mechanism of Ti-Cr-V system alloys is adding a certain amount of $\mathrm{Cr}$ and $\mathrm{V}$ in the titanium matrix. The burning product $\mathrm{Cr}_{2} \mathrm{O}_{3}$ is stable and dense and forms a protective oxide film to protect the titanium matrix from oxygen [35,67-69]. Further, $\mathrm{V}_{2} \mathrm{O}_{5}$ shows a low melting point and is easy to volatilize and it takes away a great deal of heat by either melting or volatilization during the combustion $[38,70,71]$. Hence, the Ti-Cr-V system alloys avoid combustion to some extent. The combustion behavior and mechanism of Ti40 were studied, and some results show that the 
relationship of contact force and oxygen concentration corresponding to combustion is parabolic [35,70]. The other studies reported that the burn resistance of Ti40 was higher by $40 \%$ and $20 \%$ than that of TC4 and TC11, respectively $[33,34]$. The microstructure of titanium alloys after combustion is shown in Figure 8. The microstructures are similar to those of stainless steels and nickel superalloys, which have an oxide zone, melting zone, and heat-affected zone. Different from $\mathrm{Ti}-\mathrm{Cr}-\mathrm{V}$ alloys, Ti-Cu system burn-resistant alloys are designed from the friction principle [38]. Copper shows excellent thermal conduction to avoid heat accumulation, and the eutectic structure is formed, which shows the low melting point in the temperature range of $955-990{ }^{\circ} \mathrm{C}$ when the $\mathrm{Cu}$ content is 17 wt \% [72,73]. The eutectic structure melts when the temperature is above $955^{\circ} \mathrm{C}$ and serves the liquid phase as a lubricant $[74,75]$. Then, the dry friction is transported to wet friction, which reduces the friction power and heat effectively [76,77]. Meanwhile, a Cu-enriched layer is found in the interface between the melting zone and the matrix to hinder the combustion [39].

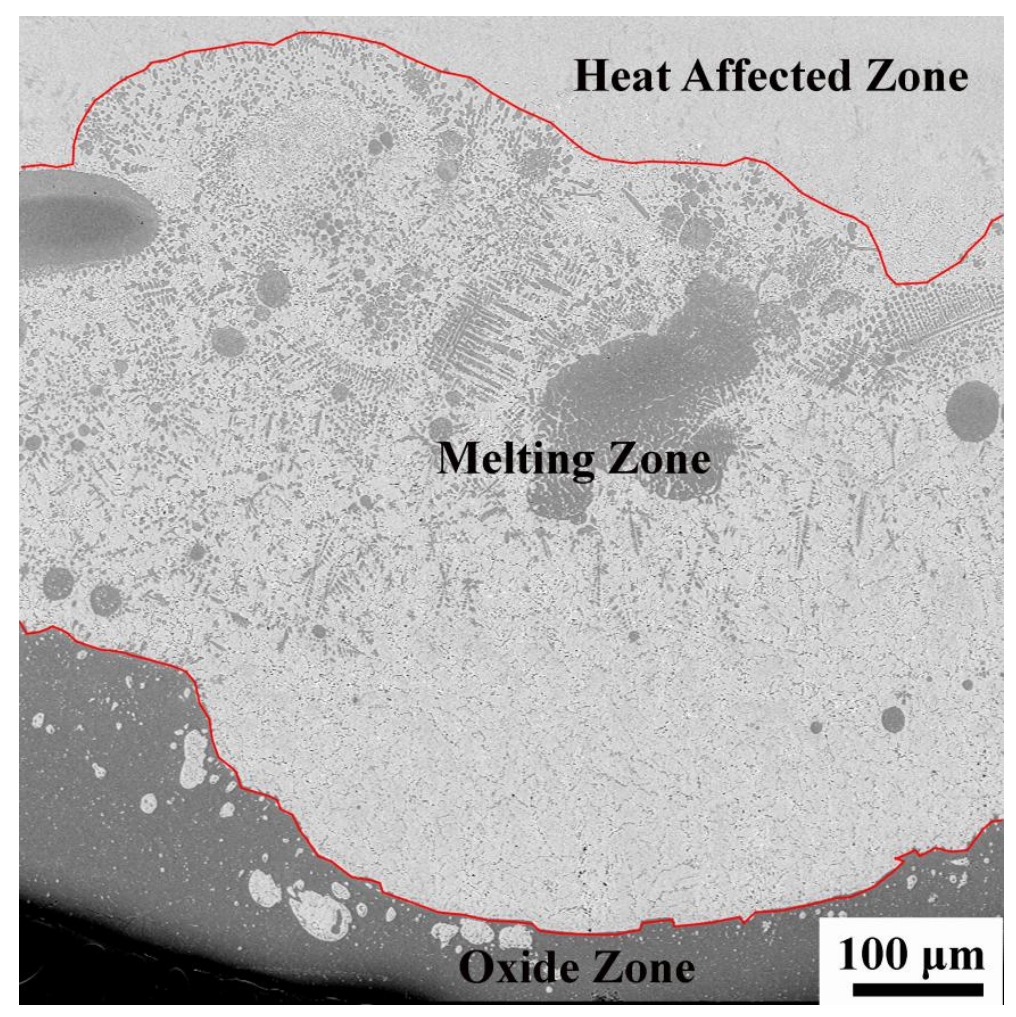

Figure 8. SEM of combustion area of titanium alloys, reproduced from [69] with permission from Shao, L. et al., 2016.

\section{Summary}

Much research on the flammability and sensitivity of materials in oxygen-enriched atmospheres has been conducted to evaluate the service safety, with a large amount of experimental data determined. However, the data are not universally available and are not always consistent. The following issues mainly exist in the combustion of metals in oxygen-enriched atmospheres:

(1) The mechanism of metals combustion in oxygen-enriched atmospheres is still unclear. Metals combustion is a complex problem touching upon many subjects such as material science, hydromechanics and physics, and the ignition mechanism is complicated. Works on metals combustion in oxygen-enriched atmospheres have only recently begun, consisting of only exploratory researches. 
(2) The repeatability of the test results is poor. There are so many factors that influence the flammability, such as configuration, size, temperature, gravity, and oxygen pressure.

(3) There is a major gap between the experimental study and field application. Researchers used some application principles and sorted the materials according to their burn-resistant properties only. However, there are still some abnormal phenomena.

The developing trends of metals combustion in oxygen-enriched atmospheres are mainly shown in the following aspects:

(1) Establishing the test standards of metals combustion in oxygen-enriched atmospheres.

(2) Studying the mechanism of metals combustion in oxygen-enriched atmospheres and building the combustion model.

(3) Designing more burn-resistant alloys to use in oxygen-enriched atmospheres.

Author Contributions: Conceptualization, J.H.; methodology, X.L. and W.L.; formal analysis, C.Z.; investigation, L.S.; data curation, L.S.; writing—original draft preparation, L.S.; writing-review and editing, L.S. and G.X.; visualization, L.S. and G.X.; supervision, G.H.; project administration, J.H.; funding acquisition, J.H. All authors have read and agreed to the published version of the manuscript.

Funding: This research received no external funding.

Conflicts of Interest: The authors declare no conflicts of interest.

\section{References}

1. Wang, H.L.; Huang, J.F.; Lian, Y.; Cheng, Z.; Zhou, Q.M.; Li, S.K.; Xuan, T. Combustion behavior of GH4169 and GH4202 superalloys in oxygen-enrichedatmosphere. Chin. J. Eng. 2016, 9, 1288-1295.

2. Neary, R.M. ASTM G63: A Milestone in a 60-year Safety Effort. In Flammability and Sensitivity of Materials in Oxygen-Enriched Atmosphere; ASTM: Phoenix, AZ, USA, 1983.

3. Bryan, C.J. NASA mechanical impact testing in high-pressure oxygen. Can. Med. Assoc. J. 1983, 88, 642.

4. Clark, A.F.; Hust, J.G. A Review of the Compatibility of Structural Materials with Oxygen. AIAA J. 1974, 12, 441-454. [CrossRef]

5. Monroe, R.W.; Bates, C.E.; Pears, C.D. Metal Combustion in High-Pressure Flowing Oxygen. In Flammability and Sensitivity of Materials in Oxygen-Enriched Atmosphere; ASTM: Phoenix, AZ, USA, 1983.

6. Sato, J.I.; Ohtani, H.; Hirano, T. Ignition Process of a Heated Iron Block in High-Pressure Oxygen Atmosphere. Combust. Flame 1995, 100, 376-383. [CrossRef]

7. Blandin, J.; Grosjean, E.; Suery, M.; Kumar, N.R.; Mebarki, N. Ignition Resistance of Various Magnesium Alloys. In Magnesium Technology; Springer: Columbus, OH, USA, 2004.

8. Shih, T.S.; Wang, J.H.; Chong, K.Z. Combustion of magnesium alloys in air. Mater. Chem. Phys. 2004, 85, 302-309. [CrossRef]

9. Kim, Y.M.; Yim, C.D.; Kim, H.S. Key factor influencing the ignition resistance of magnesium alloys at elevated temperatures. Scr. Mater. 2011, 65, 958-961. [CrossRef]

10. Czerwinski, F. Controlling the ignition and flammability of magnesium for aerospace applications. Corros. Sci. 2014, 86, 1-16. [CrossRef]

11. Lin, P.; Zhou, H.; Li, W.; Sun, N.; Yang, R. Interactive effect of cerium and aluminum on the ignition point and the oxidation resistance of magnesium alloys. Corros. Sci. 2008, 50, 2669-2675. [CrossRef]

12. Zhao, S.; Zhou, H.; Zhou, T.; Zhang, Z.; Lin, P.; Ren, L. The oxidation resistance and ignition temperature of AZ31 magnesium alloy with additions of $\mathrm{La}_{2} \mathrm{O}_{3}$ and La. Corros. Sci. 2013, 67, 75-81. [CrossRef]

13. Liu, C.; Lu, S.; Fu, Y. Flammability and the oxidation kinetics of the magnesium alloys AZ31, WE43, and ZE10. Corros. Sci. 2015, 100, 177-185. [CrossRef]

14. Kumar, N.V.; Blandin, J.J.; Suery, M. Effect of alloying elements on the ignition resistance of magnesium alloys. Scr. Mater. 2003, 49, 225-230. [CrossRef]

15. Fan, J.F.; Chen, Z.Y.; Yang, W.D.; Fang, S.; Xu, B.S. Effect of yttrium, calcium and zirconium on ignition-proof principle and mechanical properties of magnesium alloys. J. Rare Earths 2012, 30, 74-78. [CrossRef]

16. Prasad, A.; Shi, Z.; Atrens, A. Influence of Al and $\mathrm{Y}$ on the ignition and flammability of Mg alloys. Corros. Sci. 2012, 55, 153-163. [CrossRef] 
17. Zhao, H.J.; Zhang, Y.H.; Kang, Y.L. Effect of cerium on ignition point of AZ91D magnesium alloy. China Foundry 2008, 5, 32-35.

18. Zeng, X.Q.; Wang, Q.D.; Lu, Y.Z.; Ding, W.J.; Lu, C.; Zhu, Y.P.; Zhai, C.Q.; Xu, X.P. Study on ignition proof magnesium alloy with beryllium and rare earth additions. Scr. Mater. 2000, 43, 403-409. [CrossRef]

19. Kasprzak, W.; Sokolowski, J.; Sahoo, M.; Dobrzanski, L. Thermal and structural characteristics of the AM50 magnesum alloy. J. Achievments Mater. Manuf. Eng. 2008, 28, 131-138.

20. Fassell, W.; Gulbransen, L.; Lewis, J.; Hamilton, J. Ignition temperature of magnesium and magnesium alloys. JOM 1951, 3, 522-528. [CrossRef]

21. Mebarki, N.; Kumar, R.; Blandin, J.; Sery, M.; Pelloux, F.; Khelifati, G. Correlation between ignition and oxidation behaviors of AZ91 magnesium alloy. Mater. Sci. Technol. 2005, 21, 1145-1151. [CrossRef]

22. Xu, S.; Edet-Ikpi, M.; Dong, J.; Wei, J.; Ke, W.; Chen, N. Effect of cadmium on the corrosion and mechanical properties of magnesium. Int. J. Electrochem. Sci. 2012, 7, 4735-4755.

23. Moser, Z.; Gasior, W.; Wypartowicz, J.; Zabdyr, L. The Cd-Mg (Cadmium-Magnesium) system. Bull. Alloy Phase Diagr. 1984, 5, 23-30. [CrossRef]

24. Dreizin, E.L. On the Mechanism of Asymmetric Aluminum Particle Combustion. Combust. Flame 1999, 117, 841-850. [CrossRef]

25. Tayal, M.; Wilson, D.B.; Stoltzfus, J.M. Influence of Alloying Additions on the Flammability of Ni-Based Alloys in an Oxygen Environment. In Flammability and Sensitivity of Materials in Oxygen-Enriched Atmosphere; ASTM: Denver, CO, USA, 1997.

26. Slusser, J.W.; Miller, K.A. Selection of Metals for Gaseous Oxygen Service. In ASTM Symposium on Flammability and Sensitivity of Materials in Oxygen Enriched Atmospheres; ASTM: Phoenix, AZ, USA, 1982.

27. Kirschfeld, L. Combustion of Non-Iron Heavy Metal Wires in Oxgen. Metall 1960, 14, 792-796.

28. Slusser, J.M.; Miller, K.A. Selection of Metals for Gaseous Oxygen Service. In Flammability and Sensitivity of Materials in Oxygen-Enriched Atmosphere; ASTM: Phoenix, AZ, USA, 1983.

29. Borisova, Y.A.; Sklyarov, N.M. Fireproof titanium alloys. Phys. Metallogr. 1993, 6, 21-24.

30. Zhao, Y.Q.; Zhou, L.; Deng, J. Effects of the alloying element $\mathrm{Cr}$ on the burning behavior of titanium alloys. J. Alloys Compd. 1999, 284, 190-193.

31. Chen, Y.N.; Huo, Y.Z.; Song, X.D.; Bi, Z.Z.; Gao, Y.; Zhao, Y.Q. Burn-resistant behavior and mechanism of Ti14 alloy. Int. J. Miner. Metall. Mater. 2016, 23, 215-221. [CrossRef]

32. Wang, B.; Tian, W. Combustion Morphology and Mechanism Analysis of Titanium Alloy TC4. Gas Turbine Exp. Res. 2013, 3, 50-52.

33. Dreizin, E.L. Phase changes in metal combustion. Prog. Energy Combust. Sci. 2000, 26, 57-78. [CrossRef]

34. Yu, J.L.; Zhang, X.Y.; Zhang, Q.; Wang, L.B.; Ji, K.; Peng, L.; Gao, W. Combustion behaviors and flame microstructures of micro-and nano-titanium dust explosions. Fuel 2016, 181, 785-792. [CrossRef]

35. Mi, G.B.; Cao, C.X.; Huang, X.; Cao, J.X.; Wan, B. Ignition Resistance Performance and Its Mechanism of TC11 Titanium Alloy for Aero-Engine. J. Aeronaut. Mater. 2014, 34, 83-91.

36. Tian, W.; Wang, B. Combustion Characteristics of Titanium Alloy TC11. Gas Turbine Exp. Res. 2012, 3, 40-43.

37. Mi, G.B.; Huang, X.; Cao, J.X. Frictional ignition of Ti40 fireproof titanium alloys for aero-engine in oxygen-containing media. Trans. Nonferr. Met. Soc. China 2013, 23, 2270-2275. [CrossRef]

38. Chen, Y.N.; Yang, W.Q.; Arixin, B.; Zhan, H.F.; Zhang, F.Y.; Zhao, Y.Q.; Zhao, Q.Y.; Wan, M.P.; Gu, Y.T. Underlying burning resistant mechanisms for titanium alloy. Mater. Des. 2018, 156, 588-595. [CrossRef]

39. Zhu, K.Y.; Zhao, Y.Q.; Qu, H.L. Microstructure and properties of burn-resistant Ti-Al-Cu alloys. J. Mater. Sci. 2000, 35, 5609-5612. [CrossRef]

40. Wilson, D.B.; Stoltzfus, J.M. Metals Flammability: Review and Model Analysis. ASTM Spec. Tech. Publ. 2000, 9, 28-35.

41. Bryan, C.J. NASA Mechanical Impact Testing in High-Pressure Oxygen. In Flammability and Sensitivity of Materials in Oxygen-Enriched Atmosphere; ASTM: Phoenix, AZ, USA, 1983.

42. Moffett, G.E.; Schmidt, N.E.; Pedley, M.D. An evaluation of the liquid oxygen mechanical impact test. ASTM Spec. Tech. Publ. 1989, 14, 11-22.

43. Lockhart, B.J.; Bryan, C.J.; Hampton, M.D. The oxygen sensitivity compatibility ranking of several materials by different test methods. ASTM Spec. Tech. Publ. 1989, 14, 93-105. 
44. Hirsch, D.; Hshieh, F.Y.; Beeson, H.; Bryan, C. Ignitibility in Air, Gaseous Oxygen and Oxygen-Enriched Environments of Polymers Used in Breathing-Air Devices. In Flammability and Sensitivity of Materials in Oxygen-Enriched Atmosphere; ASTM: Phoenix, AZ, USA, 1997.

45. Bryan, C.J. A Review of Test Methods Used in the Selection of Materials for Oxygen Service: Keynote Address. In Flammability and Sensitivity of Materials in Oxygen-Enriched Atmosphere; ASTM: West Conshohocken, PA, USA, 2000.

46. ASTM. ASTM G124 Standard Test Method for Determining the Burning Behavior of Metallic Materials in Oxygen-Enriched Atmospheres, Annual Book of ASTM Standards; ASTM Int.: West Conshohocken, PA, USA, 2010; Volume 14.04, pp. 1-10.

47. Sircar, S.; Stoltzfus, J.; Bryan, C.; Kazaroff, J. Promoted Combustion of Pure Metals in Oxygen-Enriched Atmospheres. In Flammability and Sensitivity of Materials in Oxygen-Enriched Atmosphere; ASTM: Philadelphia, PA, USA, 1995.

48. Benz, F.J.; Stoltzfus, J.M. Ignition of Metals and Alloys in Gaseous Oxygen by Fractional Heating. In Flammability and Sensitivity of Materials in Oxygen-Enriched Atmosphere; ASTM: Washington, DC, USA, 1986.

49. Jenny, R.; Wyssmann, H. Friction-Induced Ignition in Oxygen. In Flammability and Sensitivity of Materials in Oxygen-Enriched Atmosphere; ASTM: Phoenix, AZ, USA, 1983.

50. Benz, F.J.; Williams, R.E.; Armstriong, D. Ignition of metals and alloys by high-velocity particals. In Flammability and Sensitivity of Materials in Oxygen-Enriched Atmosphere; ASTM: Washington, DC, USA, 1986.

51. Dees, J.; Forsyth, E.; Gunaji, M.V. An Evaluation of Polymers as Ignition Sources During Particle Impact in Oxygen. In Flammability and Sensitivity of Materials in Oxygen-Enriched Atmosphere; ASTM: Philadelphia, PA, USA, 1995.

52. Wit, J.D.; Steinberg, T.A.; Haas, J.P. ASTM G 124 test data for selected Al-Si alloys, Al-composites, binary alloys and stainless steels. In Flammability and Sensitivity of Materials in Oxygen-Enriched Atmosphere; ASTM: West Conshohocken, PA, USA, 2000.

53. Steinberg, T.A.; Rucker, M.A.; Beeson, H.D. Promoted combustion of nine structural metals in high-pressure gaseous oxygen; a comparison of ranking methods. ASTM Spec. Tech. Publ. 1989, 14, 54-75.

54. Benz, F.J.; Shaw, R.C.; Homa, J.M. Burn propagation rates of metals and alloys in gaseous oxygen. In Flammability and Sensitivity of Materials in Oxygen-Enriched Atmosphere; ASTM: Washington, DC, USA, 1986.

55. Slockers, M.J.; Robles, C.R. Ignition of Metals at High Temperatures in Oxygen. J. ASTM Int. 2006, 3, 1-18. [CrossRef]

56. Mcilroy, K.; Zawierucha, R.; Million, J.F. Promoted Ignition-Combustion Behavior of Alternative High Performance Engineering Alloys in Oxygen-Enriched Atmospheres. ASTM Spec. Tech. Publ. 1997, 18, 157-169.

57. Million, J.F.; Samant, A.V. Zawierucha, R Promoted Ignition-Combustion Behavior of Cobalt and Nickel Alloys in Oxygen-Enriched Atmospheres. J. ASTM Int. 2009, 6, 1-8. [CrossRef]

58. Mcllroy, K.; Zawierucha, R. The Effects of Testing Methodology on the Promoted Ignition-Combustion Behavior of Carbon Steel and 316L Stainless Steel in Oxygen Gas Mixtures. In Flammability and Sensitivity of Materials in Oxygen-Enriched Atmospheres; ASTM: Philadelphia, PA, USA, 1989.

59. Wilson, D.B.; Steinberg, T.A.; Dewit, J.R. The presence of excess oxygen in burning metallic materials. In Flammability and Sensitivity of Materials in Oxygen-Enriched Atmosphere; ASTM: West Conshohocken, PA, USA, 2000.

60. Zhao, Y.Q.; Xi, Z.P.; Qu, H. Current situation of titanium alloy materials used for national aviation. J. Aeronaut. Mater. 2003, 23, 215-219.

61. Qian, J.H. Application and developement of new titanium alloys for aerospace. Chin. J. Rare Met. 2000, 24, 218-223.

62. Millogo, M.; Bernard, S.; Gillard, P.; Frascati, F. Combustion properties of titanium alloy powder in ALM processes: Ti6Al4V. J. Loss Prev. Process Ind. 2018, 56, 254-261. [CrossRef]

63. Zhang, G.H.; Zhang, P.Z.; Huang, G.Q.; Peng, X.; Zheng, S.Q. Study on the burn-resistant properties of Titanium alloy Ti-6Al-4V surface by diffusing copper. Rare Metal Mater. Eng. 2011, 40, 286-289.

64. Shao, L.; Xie, G.L.; Liu, X.H.; Wu, Y.; Yu, J.B.; Wang, Y.Y. Combustion behaviour and mechanism of a $\mathrm{Cu}-\mathrm{Ni}-\mathrm{Mn}$ alloy in an oxygen enriched atmosphere. Corros. Sci. 2019, 108253. [CrossRef]

65. Zhao, Y.Q.; Zhao, X.M.; Zhu, K.Y. Effect of major alloying elements on microstructure and mechanical properties of a highly stabilized titanium alloy. Alloy. Compd. 2009, 481, 190-194. [CrossRef] 
66. Zhao, Y.Q.; Zhu, K.Y.; Qu, H.L.; Wu, H. Microstructures of a burn resistant highly stabilized titanium alloy. Mater. Sci. Eng. A 2000, 282, 153-157. [CrossRef]

67. Zhao, Y.Q.; Zhou, L.; Deng, J. Study on the burning behavior of Ti-Cr binary. alloys and their burning products. J. Aeronaut. Mater. 2001, 1, 6-9.

68. Xin, S.W.; Zhao, Y.Q.; Zeng, W.D.; Wu, H. Research on thermal stability of Ti40 alloy at $550{ }^{\circ}$ C. Mater. Sci. Eng. A 2008, 477, 372-378. [CrossRef]

69. Shao, L.; Wang, Y.; Xie, G. Combustion Mechanism of Alloying Elements Cr in Ti-Cr-V Alloys. Materials 2019, 12, 3206. [CrossRef]

70. Mi, G.B.; Huang, X.; Cao, J.X.; Cao, C.X. Ignition resistance performance and its theoretical analysis of Ti-V-Cr type fireproof titanium alloy. Acta Metall. Sin. 2014, 50, 575-586.

71. Zhao, Y.Q.; Zhou, L.; Zhou, Y.G.; Qu, H.L.; Wu, H.; Yang, H.Y. Research on basic theories of Ti40 burn resistant titanium alloy. J. Aeronaut. Mater. 2006, 26, 233-237.

72. Hayama, A.O.; Andrade, P.N.; Cremasco, A. Effects of composition and heat treatment on the mechanical behavior of Ti-Cu alloys. Mater. Des. 2014, 55, 1006-1013. [CrossRef]

73. Park, S.H.; Lim, K.R.; Na, M.Y. Oxidation behavior of Ti-Cu binary metallic glass. Corros. Sci. 2015, 99, 304-312. [CrossRef]

74. Souza, S.A.; Afonso, C.R.; Ferrandini, P.L. Effect of cooling rate on Ti-Cu eutectoid alloy microstructure. Mater. Sci. Eng. C 2009, 29, 1023-1028. [CrossRef]

75. Cardoso, F.F.; Cremasco, A.; Contieri, R.J. Hexagonal martensite decomposition and phase precipitation in Ti-Cu alloys. Mater. Des. 2011, 32, 4608-4613. [CrossRef]

76. Chen, Y.N.; Yang, W.Q.; Bo, A.X.; Zhan, H.F.; Huo, Y.Z. Tailorable Burning Behavior of Ti14 Alloy by Controlling Semi-Solid Forging Temperature. Materials 2016, 9, 697. [CrossRef]

77. Kikuchi, M.; Takada, Y.; Kiyosue, S.; Yoda, M.; Woldu, M.; Cai, Z.; Okuno, O. Mechanical properties and microstructures of cast Ti-Cu alloys. Dent. Mater. 2003, 19, 174-181. [CrossRef]

(C) 2020 by the authors. Licensee MDPI, Basel, Switzerland. This article is an open access article distributed under the terms and conditions of the Creative Commons Attribution (CC BY) license (http://creativecommons.org/licenses/by/4.0/). 